\title{
Improving Formwork Using Lean Tools
}

\author{
Chien-Ho K $0^{1^{*}}$, and Jiun-De K uo ${ }^{2}$ \\ ${ }^{1} \mathrm{C}$ ollege of A rchitecture, Arts and Humanity, Clemson U niversity, USA \\ ${ }^{2}$ Department of Civil Engineering, $\mathrm{N}$ ational Pingtung U niversity of Science and Technology, Taiwan
}

\begin{abstract}
M$ aterials for modules and payments for your workers are some of the main expenses for the concrete structures with stiffness. In view of this, module construction is one of the essential factors if the project succeeds or not. Traditional module construction that is involved in those activities without adding values results in wastes. This study aimed at adopting a compact method to reduce waste in the module works. The compact module construction model is developed to achieve this goal. Andon of this model is made use of build a spot assurance system. Labours can be assisted immediately in case of any issues are raised. B esides A ndon, module processes are introduced to the Kanban system to decrease mold stock and fulfil the flow of process behind ceaseless work. There was one real case discussed to verify if the proposed module applies to all. A pplication findings indicate that the developed method is able to conduct mandatory banishment in the module flow of the process and add value in the operation.
\end{abstract}

Keywords: K anban system, compact, module, A ndon.

\section{Introduction}

Module operations depend on teamwork substantially. However, elder workers may deteriorate productivity. This worker structural problem directly impacts deliverables in the project and performance, as well as cost $[1,2]$. For the purposes of improving the aforementioned problems, scholars have suggested other materials, including paper, fabric, fibre, Fiber-Reinforced Plastic (FRP), metal, compound, and composite materials to substitute wooden molds [3-6].

Lean manufacturing is a management rationale utilized by firms to improve flow in recent years. The construction industry introduced the compact production concept named Lean Construction since the '90s [7]. A variety of studies proved that compact construction may be able to replenish the construction industry with another kind of philosophy in the management [7-10]. Lean construction could make a breakthrough in the limit of traditional construction costs and time in the trade [11]. The purpose of this research was to apply a compact manufacturing mode to eliminate waste in module engineering. This paper started with the introduction of background in the study hereof, wherein production waste, Kanban,

* Corresponding author: eppm.journal@gmail.com 
and Andon were illustrated, followed by the practice of module construction and development of a compact module construction process. At last, we validated the applicability of the suggested approach through Case Study herein and also finalized conclusions and direction for any researches in the future.

\section{Background}

\subsection{Kanban}

Kanban means a signboard, billboard, bulletin board, and card generally in the Japanese language [12]. Kanban originates from a stamping line of production at the Toyota manufacturing site [13]. The post-supplementary production pursued by a stamping production line is considered as a production signal if we view it from the perspective of consumptive material. Decreased inventory of the storage site supports it directly; here come three types of Kanban at Toyota Production System as follows [14]:

Kanban for production

It is a tool used at the interval between the storage site containing finished products and the production line. It plays the role of triggering the production in a post-supplementary production system.

Kanban for Material Pick-up

This kind of Kanban is used by workers to take the required parts from the storage yard and record any item with its respective number of parts to be collected.

Mark and management Kanbans

This Kanban is a board placed on the facility, which is to be differentiated by two kinds. One of them enables to display of information to everyone and the other one focuses on displaying administrative figures.

\subsection{Andon}

Andon originates from a kind of loom that was originated from Sakichi Toyoda. It stops and the alarm lamp lights up when the device detects the broken yarns. Toyota Motor is conducted with quality control with this concept. There is an error sensor installed on production equipment, and it stops automatically when the sensor detects a fault. Toyota Motor also authorizes workers to press the button or pull the Andon Cord to stop the production line when they find a problem or need help to solve problems. Nowadays such an alarm system means a signal-based help [12].

\section{Module Process for Operation}

Module operational process shall consist of a total of 10 steps as follows, that is: 1) planning and designing, 2) shop drawing \& preparation, 3) material preparation, 4) mold machining, 5) setting out, 6) module assembly, 7) inspection, 8) monitoring and remedy of concrete pouring, 9) stripping and 10) re-supporting module, please refer to Figure 1 [15]. Contractors design module system and subcontractors prepare for shop drawings and materials according to the module system. Module subcontractors also will consult for mold inventory and hardware fittings, with which reordering any materials from material vendors as per request in case of shortage. Molds are positioned prior to assembly. The module subcontractor has to review if they are set to correct for the machining process, followed by assembly. Modules are assembled with third parties, i.e. piping, rebar, and wiring. During pouring concrete into the mold, module subcontractors shall assign a module engineer to avoid a collapse of the 
module and take care of emergent explosion, if any. Molds are stripped based on codes for recycled use in the next one or next project or storage yard.

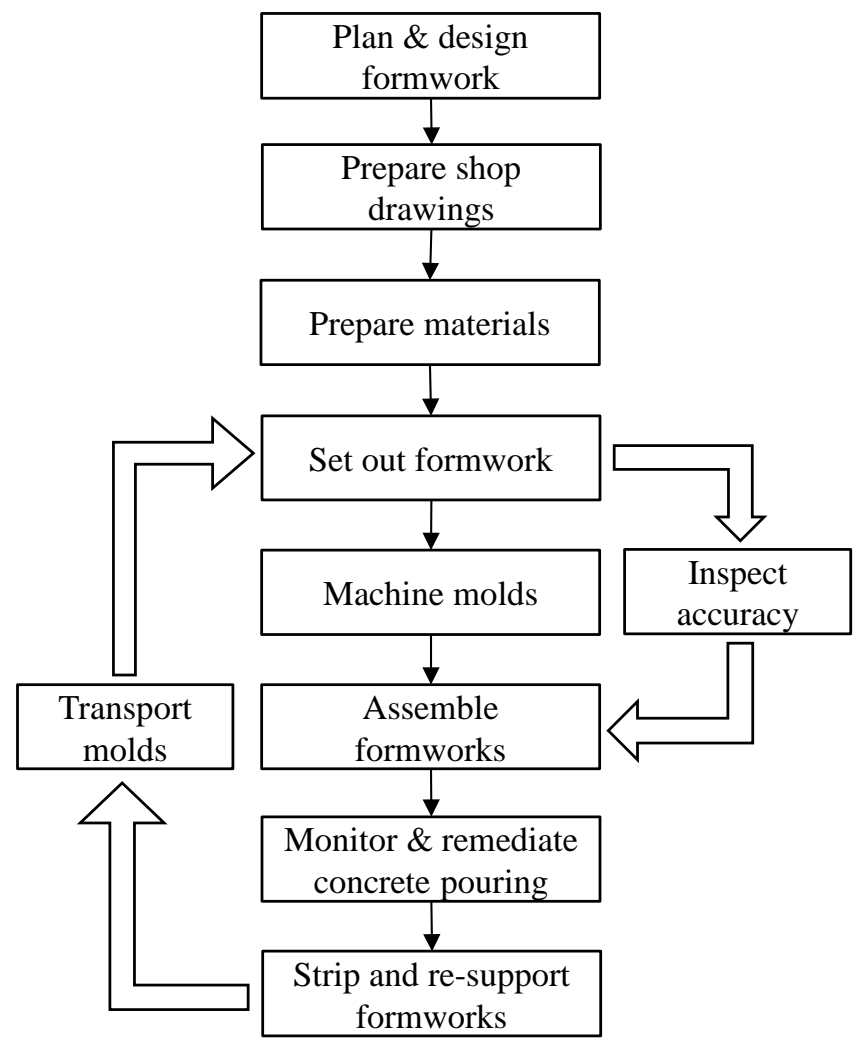

Fig 1. Module Flow of Process [16]

Any defects occurred to the module system would mostly lead to collapse or deformation, thereby causing unsuccessful result during pouring concrete in case of none of the remedies taken by field workers. The main reason could be attributed to the disputed quality assurance (QA) process, which resulted in wasteful defective products. Such issues require services with extra expenditure incurred with follow-up procedures, time, energy and waste.

\section{Lean Module}

The module system is built from the design done by the general contractor. Insofar it has seldom emphasis on the quality it is built, or any improvement of quality based on nature, thereby leading to a versified level of quality. A module system with poor performance may bulge, even falling apart. In addition, the random piled up molds in the piling field which extends duration in the search and further procedures [17]. We used Andon and Kanban systems to establish a compact module construction model in the troubleshooting. Andon is primarily utilized in the settings of performance assurance sentiment, while the Kanban system enables to reduce material stock. For the framework of the compact module construction model, please refer to Figure 2. 
Toyota Mode adds significance to the setting of the performance assurance culture, among of which, the production line will not restart until solutions are given [18]. Amid a compact working module, Andon system is used to help module workers stop works and ask for help in the occurrence of problems. During establishing this culture, module workers are educated that support is constantly available and no one will be fined in case of any issue, with which no worry is needed; improvement of performance forms a culture of cooperation and Andon tool is to develop a quality management system that emphasizes QA process primarily, which also helps engaged partners (i.e. general contractor, module subcontractor, third parties) identify and give solutions. However, the burden of pressure rises up in case of any suspension, i.e. delivery and extra costs thereof; in this case, the entire team shall identify solutions accordingly, or it causes excessive waste. Another reason is that we made use of the Andon tool to have effective control over further issues. Module subcontractors, in general, considered workers as the parties whom they shall attribute any errors or mistakes, while only improper system, flow and methods are traced for any mistakes in the compact construction module. Teammates make efforts in formulating a more effective system, instead of defending themselves.

Kanban system is used to alternate ways of oral confirmation of orders, which responds to customer requests and reduces the potential amount of waste from the materials in the storage yard and used as a base for communication to give solutions among superintendents, module foreman and workers. The flow of module construction is thereby created to control progress.

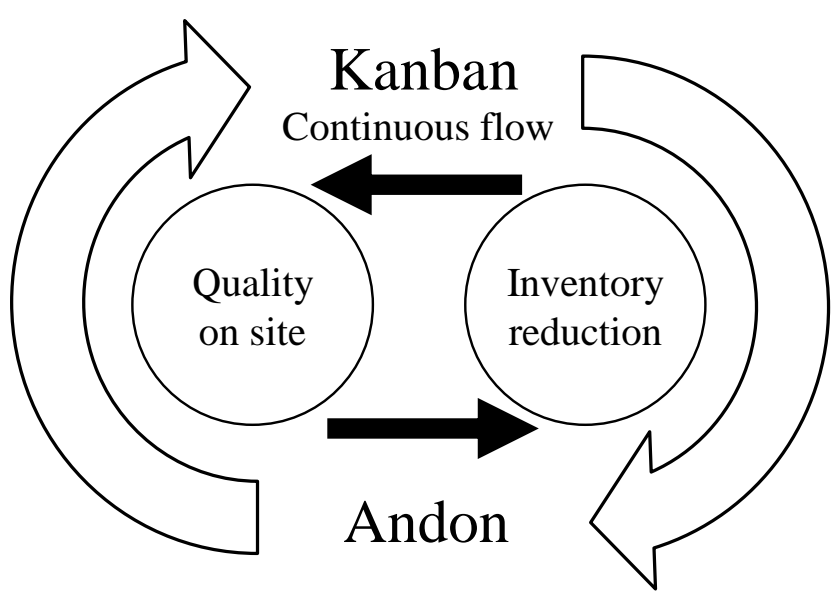

Fig 2 L ean M odule Schema [19]

\section{Case Study}

We used a real case to make an illustration of the feasibility of the proposed compact construction module. The cased building, situated in Pingtung of Taiwan, has a basement with four stories, which accounts for 2185.3 square meters; module construction on the $2^{\text {nd }}$ floor was taken as the subject in the case, which accounts for 1646 square meters. Wooden molds and supports, steel tubes and shaped steel were utilized in the construction, among of which, it also has scaffold, steel bar, electromechanical, and concrete engineering works; please refer to Table 1 for total hours module workers spend in the construction. 
Table 1: M odule Construction Hours by Workers

\begin{tabular}{ccc}
\hline A ctivity & W $^{\text {Sorkers }}{ }^{1}$ & Total hours $^{2}$ \\
\hline Prepare storage yard & 0.5 & 4 \\
A ssemble and machine mold & 2 & 16 \\
Strip mold & 140.5 & 1124 \\
A rrange mold & 26.5 & 212 \\
Transport mold & 14.25 & 114 \\
& 35 & 282 \\
\hline
\end{tabular}

${ }^{1} 1$ worker $=1$ worker has 8 hours of work.

${ }^{2}$ total hours $=$ W orkers $* 8$ hours.

For module assembly and machined process, movements including measure, pull, cut, pass, nail, and mend add value while walk, search, and wait for waste. Transportation of mold generates value; however, the on-hold moments are wastes. Appropriate layout of the site reduces movements without incremental value, such as by foot, wait while assembling and machining, as well as transporting module, hence, efficiency shall be improved.

Elimination of movements without incremental value like by foot, search and wait in assembling, machining and transportation of modules may decline a total of 570.24 worker-hours (i.e. 71.28 workers), while the proposed method may reduce 437.28 workerhours waste (54.66 workers) in assembling and machining modules. Productivity increases from 11.72 to 19.18 square meters per daily worker, while it increases from 46.7 to 88.35 square meters per daily worker during transporting molds. Please refer to Figure 3 for the comparative results before/after improvement.

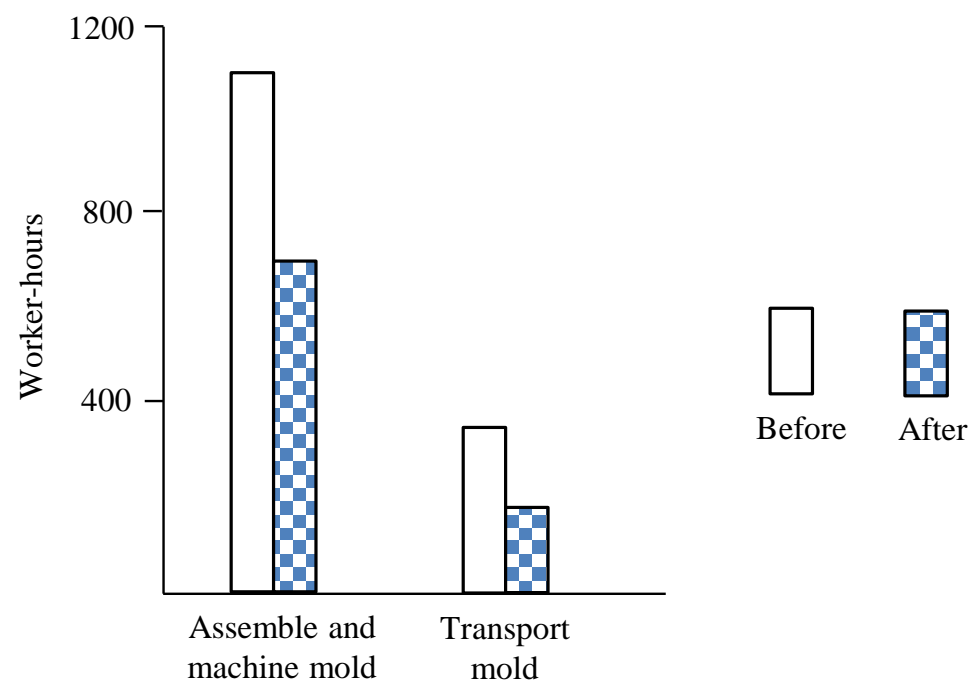

Fig. 3. W orker-H ours I mprovement 
Teamwork coming from the general contractor, module subcontractor and third parties involving the project forms a kind of free-of-plan culture leads to wasteful on-hold time among subcontractors due to loss of coordination. The result in the analysis indicated that the flow of process consists of wasteful movement and the main reason is that module foreman has no plan of layout for the construction site beforehand, thereby generating waste of movements such as walk, search, and wait during assembling, machining, and transporting molds. Furthermore, the module foreman instructs workers orally that workers may have a loss of information regarding the production. Moreover, teams generally are in the shortage of conceptual on-site quality control that workers are not sure about the process well and all of these factors constitute wastes of defects.

\section{Conclusions}

Waste is generated from current practices in assembling, machining, and transporting molds. We used a compact way to establish a compact module construction model, which is a production system based on reduced waste and value-added customer. The signals transmitted by the Kanban system are followed to reduce mold inventory.

Improved module quality depends on the attitude of learning and improving as a whole. Andon tool and Kanban system may be used to eliminate non-adding-value waste; however, foreman and superintendent also shall take the resistance of reform into consideration when they perform the transformation. Education is required behind implementing the compact module construction model. Workers may resist the reform since managerial philosophy varies between compact module construction model and current practices.

\section{Acknowledgements}

This research was funded by the Ministry of Science and Technology, Taiwan with grant number MOST 103-2221-E-020-027-MY2. Thanks are also due to the case study's general contract and formwork subcontractor, for their generous assistance.

\section{References}

1. M. Sutherland, Formwork economics, Concrete Engineering International, 9(4):18-19 (2005)

2. H.C. Chang, Productivity A nalysis of Construction Formwork in Residential Buildings, MS Thesis, Department of Civil Engineering, National Taiwan University, Taiwan (in Chinese) (2007)

3. M. A rslan, O. Simsek, S. Subasi, Effects of formwork surface materials on concrete lateral pressure, Construction and Building Materials 19(4):319-325 (2005)

4. D. V eenendaal, M. W est, P. Block, History and overview of fabric formwork: U sing fabrics for concrete casting, Structural Concrete 12(3):164-177 (2011)

5. A.J. Spottiswoode, L.C. Bank, A. Shapira, Investigation of paperboard tubes as formwork for concrete bridge decks, Construction and Building Materials 30:767-775 (2012)

6. R. Y ip, C.S. Poon, Comparison of timber and metal formwork systems, Proceedings of Institution of Civil Engineers: Waste and Resource Management 161(1):29-36 (2008)

7. L. Koskela, A pplication of the New Production Philosophy to Construction, Technical Report, Stanford University, USA (1992)

8. G. Ballard, The Last Planner System of Production Control, The University of Birmingham, PhD Thesis, UK (2000) 
9. C.H. Ko, Y.C. Chen, Evaluating Production Time Buffer for Precast Fabrication, Journal of Engineering, Project, and Production Management, 2(2):101-111 (2012)

10. C.H. Ko, Production control in precast fabrication: considering demand variability in production schedules, Canadian Journal of Civil Engineering 38(2):191-199 (2011)

11. B est and de V al ence (Editors), Building in Value: Project Delivery, John W iley $\&$ Sons, N ew Y ork (2000)

12. J.K. Liker, The Toyota Way: 14 Management Principles from the World's Greatest Manufacturer, M cGraw Hill, New Y ork (2003)

13. H.S. Li, C.C. Y ang, M eticulously Discuss Toyota Production System, Quality Monthly Journal 45(3):13-18 (2009) (in Chinese)

14. H.S. Li, C.C. Y ang, Kanban in Toyota Production System, Quality Monthly Journal 45(4):42-49 (2009) (in Chinese)

15. C.F. Shen, Formwork Engineering: Economic, Design, Assembly, and Safety, Shen, Taipei (1996) (in Chinese)

16. C.H. K o, J.D. K uo, M aking Formwork Construction L ean, Journal of Civil Engineering and Management 21(4):444-458 (2015)

17. Y.H. Peng, Consulting Service for A utomation in A rchitectural Engineering, Research Report, Architecture and Building Research Institute, M inistry of the Interior, Taipei, Taiwan (1998) (in Chinese)

18. J.K. Liker, D. M eier, The Toyota Way Fieldbook, Mc Graw Hill, New Y ork (2006)

19. C.H. K O, J.D. K uo, Lean Formwork, Proceedings of the 24nd Annual Conference of the International Group for Lean Construction, Chennai, India, 1283-1290 (2018) 